Egypt J. Aquat. BioLd Fish. Vol. 10,No.l: 151-172(2006)ＩSSN 1110-6131

\title{
ONTOGENY OF CRF- AND ACTH-SECRETING CELLS DURING DEVELOPMENT OF OREOCHROMIS NILOTIC LARVAE
}

\author{
Noha A. Khalil \\ National Institute of Oceanography and Fisheries, Fish Reproduction \\ Laboratory, alknater, Egypt.
}

Key words: Fish larvae, Oreochromis niloticus, development, CRF, ACTH, immunocytochemistry.

ABSTRACT
ntogenic development of the onset and localization of the
immunoreactivity to antibodies against corticotrophin releasing
factor (CRF) and adrenocorticotropic hormone (ACTH) was investigated
in the developing of Oreochromis niloticus larvae, by using
immunohistochemical technique, in an attempt to disclose a possible
involvement of these molecules in the early immune-endocrine
integration. The immunocytochemical analysis showed that CRF was
localized in the developing gills and digestive tract in the examined stages
of development (from 0 to 35 days post-hatching). In gills, CRF
immunoreactivity was observed in presumptive chloride cells. In the
digestive system, CRF immunoreactivity was restricted to the mucosal
epithelium of the undifferentiated digestive tube and in the gastric glands
of the stomach. Along the larval development both the number of CRF-
immunoreactive (ir) cells and the intensity of immunoreaction were
gradually increased especially after the onset of exogenous feeding at $21-$
28 days post-hatching (dph). ACTH immunoreactivity was obtained only
in the goblet cells of the developing intestine, and showed strong
immunoreaction during the period of yolk sac resorbtion at $7-10$ dph. With
the onset of exogenous feeding, ACTH-ir cells showed significant decrease
in both the number and size, and gave very weak
immunoreaction at 28 dph.
The early appearance and broad anatomic distribution of activities of CRF
and ACTH in the larvae likely indicates the functional importance of these
molecules in osmoregulation, immune response, food intake and growth
during development especially in the period after yolk sac resorption.

